\title{
Occurrence of VOCs before and after renovation of an apartment: a case study
}

\author{
S. Vilcekova \& L. Meciarova \\ Faculty of Civil Engineering, Technical University of Kosice, Slovakia
}

\begin{abstract}
Breathing is a natural need of people, but the air that we breathe is not always clean. This also applies to the air in our homes, although, many people think the opposite. Air pollution goes hand-in-hand with the current industrial period. We are more and more surrounded by materials and products on a synthetic basis and even our behaviour (smoking, cooking, etc.) does not help to improve quality of indoor air. This paper deals with the occurrence of volatile organic compounds (VOCs), regarding the fact that these compounds are considered to be the most important gaseous pollutants in indoor air. The aim of this study was to determine the current levels and the occurrence of individual VOCs in homes in Slovakia. These substances were measured during renovation works in the selected apartment. An electronic nose based on gas chromatography was used for the analysis of individual VOCs and a photoionization detector with a UV lamp was used for the determination of total volatile organic compounds (TVOC) concentration. The results have shown that applied paints were the major sources of VOCs in the indoor air. The biggest increase of TVOC concentrations was observed after application of synthetic paint.

Keywords: indoor environment, pollution, volatile organic compounds, electronic nose.
\end{abstract}

\section{Introduction}

Research conducted over the last few years indicates that indoor air pollution in non-industrial buildings is affecting human health and productivity in a significant way [1]. The health effects of indoor air pollutants are not fully understood, but indoor air quality has been linked with a wide array of health outcomes. Health consequences from indoor air can result from cumulative exposure possibly 
starting in infancy [2]. The American Society of Heating, Refrigerating and AirConditioning Engineers (ASHRAE) has elaborated recommendations for assessing indoor air, which can be considered good quality when there are no known pollutants in toxic concentrations and a substantial majority ( $80 \%$ or more) of individuals exposed express no discomfort [3].

A major pollutant in indoor air are volatile organic compounds (VOCs) emitted from materials and building products [4]. Definition by U.S. EPA is: VOC means a hydrocarbon or derivative of hydrocarbon that has a vapor pressure greater than $0.01 \mathrm{kPa}(0.002 \mathrm{psi})$ at a temperature of $20^{\circ} \mathrm{C}$ and pressure of $102.9 \mathrm{kPa}$ (14.7 psi). Excluded compounds are methane, ethane, methylene chloride, 1,1,1-trichloroethane (methyl chloroform), trichlorofluoromethane (CFC-11), dichlorodifluoromethane (CFC-12), chlorodifluoromethane (CFC-22), trifluoromethane (FC-23), trichlorotrifluoroethane (CFC-113), dichlorotetrafluoroethane (CFC-114), and chloropentafluoroethane (CFC-115) [5]. Indoor air pollution by VOCs is a particularly variable phenomenon: type and concentration of VOCs may change from one indoor space to another and concentrations may vary between different locations within the same space. In addition, there are short and long term variations of VOC concentrations with time. The obvious dynamics of indoor pollution by VOCs are mainly caused by two factors: (a) the large variety of VOC sources in the indoor environment and the diversity of their emission characteristics, and (b) the wide range of ventilation conditions and air circulation patterns [6]. In new buildings an increased exposure to chemicals is expected due to the emissions from new building materials. Whereas in most countries, no measures are performed to minimize the emissions of volatile organic compounds before occupation, there are some countries in which actions are undertaken to reduce VOC exposures by measures such as bakeout. The results, though, are contradictory [7]. Information about chemical components emitted from building materials used in many other countries is relatively scant. Notably, the emission composition of building materials is likely different among manufacturers in different countries, and current building materials exhibit different VOC emission characteristics from past materials. Moreover, new buildings are more tightly sealed so as to conserve energy, thereby establishing lower ventilation conditions. Thus, the emission characteristics of the currently-constructed buildings are not likely similar to those of buildings from the past [8]. The interior construction process of a house or apartment could last for weeks or even months. Different building materials are introduced into rooms at different times. As a result, indoor VOC concentrations during the interior construction process may vary differently as a function of time. And the variation patterns would also have effects on the estimation of short-term and long-term decay. Moreover, the indoor VOC measurements in different building construction stages may be helpful to reveal the on-site chemical composition and decay pattern of building materials. Thus, it is necessary to investigate the concentration behaviours during this period [9]. Therefore, this study deals with analysis of VOCs during renovation of selected apartment. 


\section{Materials and methods}

\subsection{Studied building}

Studied building was built in 1988 and it is located in east Slovakia (in Kosice). This residential building without basement has twelve floors and consists of 48 apartments. It is a typical residential building for Slovakia from concrete panels. Building has central heating and it is without thermal insulation. Air exchange is ensured only by natural way in each apartment. The apartment on ninth floor was chosen for this study. This is a three-room apartment, which was not occupied during the measurements. In this apartment, living room with floor area of 26.7 $\mathrm{m}^{2}$, bedroom and child's bedroom both with floor areas of $11.9 \mathrm{~m}^{2}$ were studied. First measurement was conducted before renovation in November 2014. During this measurement, there were several years old plaster and paint on the walls, PVC flooring applied in 1988 and approximately three years old white plastic windows and wooden doors in all three rooms. Paint with plaster has been removed from two walls in the child's bedroom. The second measurement was performed three days after the end of painting works (in November 2014, a week after first measurement). New plaster (based on gray cement and hydrated lime) was applied onto the one wall in the living room and onto the two walls in the child's bedroom. Gypsum as levelling compound, bonding primer (3-4 1 for one room) and white interior paint was used on the walls and ceilings in all three rooms. In the living room, there was applied also blue paint (4 1) from a different manufacturer onto the two walls. The third measurement (in December 2014, two weeks after second measurement) was carried out seven days after installation of laminate flooring which does not require the use of adhesives for installation and three days after radiators were painted with synthetic white paint. The blue paint (4 1) was also applied onto the two walls in the living room and grey paint (same manufacturer as blue paint, 2 1) was applied onto the one wall in the child's bedroom. These walls were painted five days before third measurement. The manufacturers indicates that maximum content of VOCs in the products ready to use is $2 \mathrm{~g} / \mathrm{l}$ for white paint, $3 \mathrm{~g} / \mathrm{l}$ for grey paint, $5 \mathrm{~g} / \mathrm{l}$ for blue paint, $5 \mathrm{~g} / \mathrm{l}$ for bonding primer and $300 \mathrm{~g} / 1$ for white synthetic paint for metal.

\subsection{Sampling and analysis}

Indoor air samples were taken and analysed in closed rooms, at the height approximately $1 \mathrm{~m}$ above the floor in morning hours. The owners of the apartment were asked to avoid smoking, cleaning, ventilation and the use of fragrances twelve hours before measurements. During measurements, the apartment was not heated and ventilated. The air temperature and relative humidity was set with data logger Testo $175-\mathrm{H} 2$ (measurement accuracy: $\pm 3 \% \mathrm{RH}, \pm 0.5^{\circ} \mathrm{C}$ ). Concentration of total volatile organic compounds (TVOC) expressed as concentration of toluene was measured with ppbRAE 3000, which is a photoionization detector (PID) with UV lamp. This device has a measuring range of $1 \mathrm{ppb}$ to $10000 \mathrm{ppm}$ and measurement accuracy $\pm 3 \%$. Three-second response time allows real-time 
monitoring with this instrument. Ultra-fast electronic nose called zNose ${ }^{\circledR}$, which is based on combination of gas chromatography and surface acoustic wave detector was used for sampling and analysis of individual VOCs. Manufacturer of this device specifies the standard deviation $<2 \%$. The used method includes the following settings: sensor temperature of $10^{\circ} \mathrm{C}$, column temperature of $40-200^{\circ} \mathrm{C}$, valve temperature of $165^{\circ} \mathrm{C}$, inlet temperature of $200^{\circ} \mathrm{C}$, pump time of 60 seconds $(0.5 \mathrm{ml}$ of air/s), and analysis time of 20 seconds. Capillary column DB-5 with $1 \mathrm{~m}$ length, film thickness $0.25 \mu \mathrm{m}$, and internal diameter $0.5 \mathrm{~mm}$ was used for measurement. All instruments were placed in the centre of the rooms and each measurement in each room lasted 30 minutes. The measuring time was sufficient, because both devices for determining of VOCs work quickly and allow users to see the results directly on the spot.

\section{Results}

Outdoor temperature was $8^{\circ} \mathrm{C}$ during first measurement (before painting), $7^{\circ} \mathrm{C}$ during second measurement (after painting) and $2^{\circ} \mathrm{C}$ during third measurement (after installation of flooring). The lowest mean relative humidity was $38.6 \%$ measured in living room after floor installation and the highest was $47.7 \%$ determined also in living room but before painting. The highest mean temperature was $22.1^{\circ} \mathrm{C}$ measured in child's bedroom before and also after painting. The lowest mean temperature was $18^{\circ} \mathrm{C}$ measured in living room after floor installation.

Table 1: Air temperature and relative humidity.

\begin{tabular}{|c|c|c|c|c|c|c|c|c|c|}
\hline \multirow[t]{2}{*}{$R H$} & \multicolumn{3}{|c|}{$1^{\text {st }}$ day of measurement } & \multicolumn{3}{|c|}{$2^{\text {nd }}$ day of measurement } & \multicolumn{3}{|c|}{$3^{\text {rd }}$ day of measurement } \\
\hline & Min. & Max. & Mean & Min. & Max. & Mean & Min. & Max. & Mean \\
\hline Living room & 47.1 & 49.7 & 47.7 & 43.7 & 44.9 & 44.1 & 37 & 39.8 & 38.6 \\
\hline Bedroom & 46.2 & 48.1 & 46.6 & 42.3 & 42.8 & 42.5 & 40.4 & 41.3 & 40.8 \\
\hline $\begin{array}{l}\text { Child's } \\
\text { bedroom }\end{array}$ & 46.4 & 47 & 46.5 & 39.4 & 40.6 & 40 & 39.4 & 40.2 & 39.7 \\
\hline \multicolumn{10}{|l|}{ Air temperature } \\
\hline Living room & 20 & 21.1 & 20.7 & 20.2 & 21 & 20.7 & 18 & 18 & 18 \\
\hline Bedroom & 21.5 & 22.2 & 21.9 & 21.4 & 22.2 & 21.8 & 18.3 & 18.7 & 18.6 \\
\hline $\begin{array}{l}\text { Child's } \\
\text { bedroom }\end{array}$ & 22 & 22.2 & 22.1 & 22.1 & 22.2 & 22.1 & 18 & 18.2 & 18.1 \\
\hline
\end{tabular}

As it can be seen, lower temperature measured in the apartment after floor installation corresponds to lower outdoor temperature in this day. Difference in relative humidity is $4.7 \%$ in average between first and second measurements and $7 \%$ between second and third measurements. Difference in air temperature is $0.1^{\circ} \mathrm{C}$ in average between first and second measurements and $3.3^{\circ} \mathrm{C}$ between second and third measurements. Although these differences do not appear to be high at first sight, it is probable that they also had impact on level of TVOC concentrations in individual rooms. 
Mean TVOC concentration was $113 \mu \mathrm{g} / \mathrm{m}^{3}$ before painting, $396 \mu \mathrm{g} / \mathrm{m}^{3}$ after painting and $1258 \mu \mathrm{g} / \mathrm{m}^{3}$ after installation of flooring in the living room. In the bedroom, mean TVOC concentration was $133 \mu \mathrm{g} / \mathrm{m}^{3}$ before painting, $289 \mu \mathrm{g} / \mathrm{m}^{3}$ after painting and $1246 \mu \mathrm{g} / \mathrm{m}^{3}$ after floor installation. In the child's bedroom, TVOC concentration was $143 \mu \mathrm{g} / \mathrm{m}^{3}$ before painting, $300 \mu \mathrm{g} / \mathrm{m}^{3}$ after painting and $886 \mu \mathrm{g} / \mathrm{m}^{3}$ after installation of flooring. The TVOC concentrations were highest in the living room and during third measurement day. In this room, the concentration was 11 times higher in the third measurement than in the first measurement and approximately 3 times higher than in the second measurement. Difference between living room and bedroom was only $12 \mu \mathrm{g} / \mathrm{m}^{3}$, difference between living room and child's bedroom was $372 \mu \mathrm{g} / \mathrm{m}^{3}$ and between bedroom and child's bedroom was $360 \mu \mathrm{g} / \mathrm{m}^{3}$ during third measurement. These higher concentrations can be explained by above mentioned synthetic paint used on radiators before this measurement. And concentration in living room was higher than in other rooms because blue paint was applied again onto the two walls. Reason why concentration was much lower in child's bedroom during third measurement than concentrations in other rooms was not found.

Identified compounds are shown in the Table 2. It is obvious that the most occurred compound was 2,2-dichloroisopropyl ether, which can be used as solvent for paint and varnish removers, cleaning solutions or as an intermediate in dyes [10]. Toluene [11] and undecane [12] were detected six times in indoor air. These compounds together with ethyl benzene [13] can be found in paints. Wilke et al. [4] found that these compounds were emitted also from PVC floor coverings on the $28^{\text {th }}$ day of chamber testing. In this study, longicyclene, nonanal and $\alpha$-copaen were also identified in adhesive for flooring installation and in floor coverings [4]. 1,3-Dichlorobenzene is used to make dyes [14]. Eugenol is used in manufacturing stabilizers and antioxidants for plastics and rubbers among other things [15]. Possible sources of this compound were plastic skirting stored in the hallway of apartment. 1-Tridecene is uses as solvent [16]. Compounds camphene hydrate, hexyl isobutyrate, neral, and (E)-2-hexenyl hexanoate are usually used as perfuming agents or in cosmetic products $[17,18]$. Thus their presence can be explained by presence of construction worker and person carrying out of measurement. Methyl salicylate is naturally produced by many species of plants but it is also synthetically produced and used in cosmetic products, medicinal products or as flavouring agents [19]. Carvone is a terpene natural product. Wood, wooden products and coatings are emission sources for terpenes in indoor rooms. The substances are also to be found in cleansing agents, cosmetics, air fresheners, paints, lacquers and oils. Carvone is very interesting compound, which, on the one hand, is a component in natural terpene balsam and, on the other hand, it is also a possible oxidation product of limonene [20]. $\beta$-Pinene has been identified as a volatile organic ingredient of wood-based furniture with its possible source being an ecological coating system based on natural resins, nitrocellulose, or softwood construction [21]. Thus in this case, possible source of this compound may be laminate flooring. In the study of Gallego et al. [22], 2,2,5,5-tetramethylhexane was also found in indoor air samples. 
Table 2: Identified VOCs in the indoor air.

\begin{tabular}{|c|c|c|c|c|c|c|c|c|c|}
\hline \multirow[t]{2}{*}{ Compound (CAS) } & \multicolumn{3}{|c|}{$\begin{array}{c}1^{\text {st }} \text { day of } \\
\text { measurement }\end{array}$} & \multicolumn{3}{|c|}{$\begin{array}{c}2^{\text {nd }} \text { day of } \\
\text { measurement }\end{array}$} & \multicolumn{3}{|c|}{$\begin{array}{c}3^{\text {rd }} \text { day of } \\
\text { measurement }\end{array}$} \\
\hline & LR & BR & $\mathrm{CB}$ & LR & BR & CB & LR & BR & $\mathrm{CB}$ \\
\hline Toluene (108-88-3) & & & & $*$ & * & * & * & * & $*$ \\
\hline Ethyl benzene (100-41-4) & & & & & & & * & * & $*$ \\
\hline 8-methyl-1-nonene (-) & & & & & & & * & * & $*$ \\
\hline Artemiseole (60485-46-3) & $*$ & & * & & & & & & \\
\hline 2,6-dimethyl-3-heptanone (19549-83-8) & & & & $*$ & $*$ & * & & & \\
\hline$\beta$-pinene (127-91-3) & & & & & & & $*$ & * & $*$ \\
\hline 1,3-dichlorobenzene (541-73-1) & & & & & & & $*$ & * & \\
\hline 2,2-dichloroisopropyl ether (108-60-1) & $*$ & $*$ & * & $*$ & $*$ & $*$ & & & $*$ \\
\hline 2,2,5,5-tetramethylhexane (1071-81-4) & & & & & & & * & $*$ & $*$ \\
\hline Nonanal (124-19-6) & & & & & & & & * & \\
\hline Undecane (1120-21-4) & $*$ & * & $*$ & & $*$ & & * & & $*$ \\
\hline Camphene hydrate (465-31-6) & & & & & $*$ & $*$ & & & \\
\hline Hexyl isobutyrate (2349-07-7) & & $*$ & $*$ & $*$ & & & * & $*$ & \\
\hline 6-methyloctan-2-ol (-) & $*$ & & & & & & & & $*$ \\
\hline 2-methyl acetophenone (577-16-2) & & & & & $*$ & $*$ & & & \\
\hline Methyl salicylate (119-36-8) & & & & $*$ & & & * & $*$ & \\
\hline 1-dodecene (112-41-4) & & & & & & & & & $*$ \\
\hline Neral (106-26-3) & & & & $*$ & * & $*$ & & & \\
\hline Carvone (99-49-0) & $*$ & * & & & & & * & * & \\
\hline Ethyl 2-phenylacetate (101-97-3) & & & & & & & & & $*$ \\
\hline 1-tridecene (2437-56-1) & $*$ & $*$ & $*$ & & & & & & \\
\hline Methyl geranate (2349-14-6) & $*$ & & & & & & & & \\
\hline Eugenol (97-53-0) & & & & & * & $*$ & & * & \\
\hline 4-methyltridecane (26730-12-1) & & & & & & & * & & $*$ \\
\hline (E)-2-hexenyl hexanoate (53398-86-0) & & & * & & & $*$ & & & \\
\hline$\alpha$-copaene $(3856-25-5)$ & & & & & & & & $*$ & \\
\hline Decanal dimethyl acetal (7779-41-1) & * & * & & & * & & & & \\
\hline Longicyclene (1137-12-8) & & & & & & & * & & $*$ \\
\hline 1,3-Indandione (606-23-5) & & & & $*$ & & & & & \\
\hline
\end{tabular}

1-Dodecene was reported as a compound present in the exhaust of gasoline but also was qualitatively identified as VOC released from textile floor coverings [23]. Textile floor covering were not used in this apartment thus it is possible that this compound originates from outdoor air. Potential sources of other compounds are unknown. 


\section{Conclusion}

The concentrations of TVOC slightly increased after the application of new plaster, bonding primer and paints onto the walls and ceilings. Much higher increase was recorded after installation of flooring and application of synthetic paint for radiators. This type of paint has high VOC content in the state of ready for use and emitted high concentration three days after application. Therefore it would be appropriate to avoid the use of these paints in the interior. Compounds which originate from paints were mostly identified in indoor air of apartment. We tested similar laminate flooring as had been used in the apartment in an environmental chamber with result of minimum VOCs emissions. Thus, it is possible to say that paints were major sources of VOCs in individual rooms. But it is necessary to consider the possibility that the bonding primer could also be an important source of VOCs in the indoor air. Therefore, samples of all used materials have been collected and will be tested in the environmental chamber in the second phase of research.

\section{Acknowledgement}

This study was financially supported by Grant Agency of Slovak Republic to support of project No. 1/0405/13.

\section{References}

[1] Haghighat, F. \& De Bellis, L., Material emission rates: literature review, and the impact of indoor air temperature and relative humidity. Building and Environment, 33(5), pp. 261-277, 1998.

[2] Pickett, A.R. \& Bell, M., Assessment of indoor air pollution in homes with infants. International Journal of Environmental Research and Public Health, 8(12), pp. 4502-4520, 2011.

[3] Fernández, L.C., Alvarez, R.F., González-Barcala, F.J.\& Portal, J.A.R., Indoor air contaminants and their impact on respiratory pathologies. Archivos de Bronconeumología. 49(1), pp. 22-27, 2013.

[4] Wilke, O., Jann, O., Brödner, D., VOC- and SVOC-emissions from adhesives, floor coverings and complete floor structures. Indoor Air, 14(8), pp. 98-107, 2004.

[5] United States Environmental Protection Agency. SIP - NWAPA 580,http:/yosemite.epa.gov/r10/airpage.nsf/f3f22921988a261b882569e50 05ee8bb/1 f017ea04cefcf9988256a340003bcd6?OpenDocument

[6] ECA-IAQ (European Collaborative Action "Indoor Air Quality and its Impact on Man") Sampling Strategies for Volatile Organic Compounds (VOCs) in Indoor Air, Office for Official Publications of the European Communities: Luxemburg (Report No. 14, EUR 16051 EN), 1994.

[7] Rothweiler, H., Wager, P.A. \& Schlatter, C., Volatile organic compounds and some very volatile organic compounds in new and recently renovated buildings in Switzerland. Atmospheric Environment, 59(12), pp. 2219$2225,1992$. 
[8] Shin, S.H. \& Jo, W.K., Volatile organic compound concentrations, emission rates, and source apportionment in newly-built apartments at pre-occupancy stage. Chemosphere, 89(5), pp. 569-578, 2012.

[9] Liang, W., Wang, C. Yang, C. \& Yang, X., Volatile organic compounds in different interior construction stages of an apartment. Building and Environment, 81, pp. 380-387, 2014.

[10] SPECTRUM. Chemical Fact Sheet, www.speclab.com/compound/c108601.htm

[11] United States Environmental Protection Agency. Locating and estimating air emissions from sources of toluene. Final Report. EPA Contract No. 68D9-0173, Work Assignment No. 3/316, p. 207, 1993.

[12] NCI by Technical Resources International, Inc. Summary of data for chemical selection,

www.ntp.niehs.nih.gov/ntp/htdocs/chem_background/exsumpdf/undecane 508.pdf

[13] International agency for research on cancer (IARC). Monographs on the evaluation of carcinogenic risks to humans, vol. 77, IARC: Lyon, France, pp. 227-266, 2000.

[14] Agency for Toxic Substances \& Disease Registry, www.atsdr.cdc.gov/substances/toxsubstance.asp?toxid $=126$

[15] Wikipedia, www.en.wikipedia.org/wiki/Eugenol\#cite_note-9

[16] Chemical Dictionary Online, www.chemicaldictionary.org/dic/1/1-Tri decene_2086.html

[17] Perfumer \& Flavorist, www.perflavory.com/docs/doc1008581.html

[18] Azimova, S.S., Glushenkova, A.I. \& Vinogradova, V.I., eds. Lipids, lipophilic components and essential oils from plant sources, vol. 1, Springer Science \& Business Media, p. 46, 2011.

[19] Risk profile, Methyl salicylate, www.mattilsynet.no/kosmetikk/stoffer_i_kosmetikk/risk_profile_methyl_s alicylate.9877/binary/Risk\%20Profile\%20Methyl\%20Salicylate

[20] Pluschke, P., ed. Indoor Air Pollution. Vol. 4, Springer Science \& Business Media, p. 61, 2004.

[21] Pubchem, Open chemistry database, http://pubchem.ncbi.nlm.nih.gov/compound/beta-pinene\#section=Top

[22] Gallego, E., Roca, X., Perales, F. \& Guardino, X., Methodology for determining indoor air quality and identifying the origin of odour episodes in indoor environments through dynamic VOC sampling and TD-GC/MS analysis, www.google.sk/url? sa $=\mathrm{t} \& \mathrm{rct}=\mathrm{j} \& \mathrm{q}=\&$ esrc $=\mathrm{s} \&$ source $=$ web $\& \mathrm{~cd}=1 \& \mathrm{ved}=0 \mathrm{C}$ B8QFjAA\&url=http\%3A\%2F\%2Fwww.researchgate.net\%2Fpublication $\% 2 F 41887877$ Determining_indoor_air_quality_and_identifying_the_ori gin_of_odour_episodes_in_indoor_environments $\% 2$ Ffile $\% 2$ F $79 \mathrm{e} 4150 \mathrm{~b} 47$

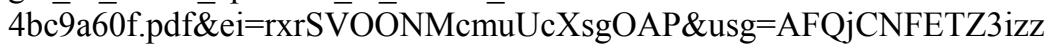
bK1vl6ulySCZfyRR8mFQ\&sig2=pOpDFpBdwXnvYQZUEZLE7A

[23] Pubchem, Open chemistry database, http://pubchem.ncbi.nlm.nih. gov/compound/1-dodecene\#section=Effluents-Concentration 